Session FA3-1

\title{
Girlgeneering vs. Entry to Engineering: Engineering Outreach Program Comparison of a Girls-Only vs. Co-Ed Engineering Summer Camp
}

\author{
Dr. Lynn Peterson, Dr. Carter Tiernan, Lynard Broussard \\ College of Engineering \\ University of Texas at Arlington
}

\begin{abstract}
This paper will provide a comparison of two one-week long engineering summer day camps that were held in Summer 2008 by the College of Engineering at the University of Texas at Arlington. One camp was a coeducational camp called Entry to Engineering for students entering $6^{\text {th }}, 7^{\text {th }}$, or $8^{\text {th }}$ grades in Fall 2008. This camp is part of the UTA Engineering and Computer Science Summer Camps that have been running since 1998. The second camp was a newly inaugurated camp called Girlgeneering. This camp was for girls entering the $6^{\text {th }}, 7^{\text {th }}, 8^{\text {th }}$ or $9^{\text {th }}$ grades in Fall 2008. The new Girlgeneering camp was modeled after the structure of the Entry to Engineering camp with some specific modifications for its audience that will be discussed.

In the paper we will discuss the goals for the two camps, the differences in the planning for the camps, and the staffing for the camps. We will also talk about our rationale for the ways in which the camps were planned differently. We will then talk about the ways in which the camps themselves were similar and were different in a variety of areas including student engagement, development of student subgroups (cliques), camper behavior, responses to camp activities, and other topics. We will include qualitative feedback from the campers and from staffers about the camps. We will close with a discussion of the benefits of the two types of camps and our plans for the future. The paper will be co-authored by the faculty camp director, the staff member camp assistant director, and will include comments from student camp staffers.
\end{abstract}

\section{Introduction}

This paper provides a comparison of two one-week long engineering summer day camps that were held in Summer 2008 by the College of Engineering at the University of Texas at Arlington. The first camp, Entry to Engineering, is a co-educational camp for students entering $6^{\text {th }}, 7^{\text {th }}$, or $8^{\text {th }}$ grades in Fall 2008. The second camp, Girlgeneering, is a girls-only camp for young women entering $6^{\text {th }}, 7^{\text {th }}, 8^{\text {th }}$ or $9^{\text {th }}$ grade in Fall 2008. The paper will give the background and history of the camps, the planning done for both camps, the camps themselves, feedback from campers and camp staff, the benefits seen for both camps and future plans for these camps.

\section{Background}

The University of Texas at Arlington College of Engineering has been conducting summer camp programs since 1998. The engineering summer camp program, headed by Dr. Lynn Peterson 
and Dr. Kendall Harris, was started under the auspices of a National Science Foundation grant to increase engineering outreach. The camps were co-educational residential camps generally a week in length targeted at middle school and high school students. In 2005, Dr. Carter Tiernan took over the summer camp program, now called the Engineering and Computer Science Summer Camps. Since that time the summer camps have changed in structure to include two one-week residential camps as well as a one-week day camp. The Summer 2008 Engineering and Computer Science camps consisted of a residential camp for incoming $9^{\text {th }}$ and $10^{\text {th }}$ graders called Bridge to Engineering, a residential camp for $7^{\text {th }}$ and $8^{\text {th }}$ graders called Gateway to Engineering, and a day camp for $6^{\text {th }}, 7^{\text {th }}$ and $8^{\text {th }}$ graders called Entry to Engineering. These Summer Camps are directed by Dr. Tiernan and Mr. Lynard Broussard, the College of Engineering Undergraduate Recruiter. In addition to the Engineering and Computer Science Summer Camps, in 2008 Dr. Tiernan and Mr. Broussard also directed a new single gender summer camp called Girlgeneering a week-long engineering day camp for girls entering the $6^{\text {th }}$, $7^{\text {th }}, 8^{\text {th }}$ or $9^{\text {th }}$ grades. All of these camps are part of the UT Arlington Engineering Summer Programs which also include other engineering workshops, programs, and camps sponsored by various engineering departments and groups at UT Arlington.

Since their initial development, the purpose of the Engineering Summer Programs has been to introduce pre-college students to engineering in a fun and exciting way that creates and increases the interest of these students and encourages them to consider degrees and careers in engineering. Since UT Arlington is home to the most diverse engineering program in North Texas, the College of Engineering presents all of these engineering areas to the campers in the summer camps which gives a broad picture of what engineering can be. By holding the camps on the UT Arlington campus the College is also able to showcase the campus and its great amenities to these potential future UT Arlington engineering students.

\section{Camp Rationale}

As with many other engineering organizations, the University of Texas at Arlington College of Engineering has been and is concerned with increasing the number of students who pursue degrees and careers in engineering and all STEM fields. Providing summer activities for precollege students is one way of introducing them to engineering and the opportunities it offers. The UT Arlington Engineering and Computer Science Summer Camps have reached more than 1500 students over the last 10 years. Follow up data from two of the early camp years showed that $100 \%$ of the campers from those years went on to college, $50 \%$ in STEM majors, and that $72 \%$ of the students felt that their camp attendance influenced their choice of major.

The Entry to Engineering camp and the other Engineering and Computer Science Summer Camps employ a number of strategies to help students connect with engineering; faculty present timely research topics to show relevance to the student, presentations are mixed with hands-on activities and/or lab visits so that many learning styles are engaged, industry/community field trips show how engineering is applied in all aspects of life, the team-based engineering project provides an engineering experience, a design process experience and a team experience as well that is realistic and fun, and the engineering camp staffers provide role models for the campers who are closer to their own age who can answer questions about college and show the diversity 
of engineering. Consistent feedback from campers shows that these strategies are effective in reaching students and teaching them about engineering.

Given these effective strategies, it is also important to look at the camp demographics to insure that this outreach is also having an impact on underrepresented groups in engineering. For 2008 the overall ethnic demographic was African-Americans 20\% and Hispanics 13\% with the remainder of students White or Asian. While we would still like to increase these percentages, they are reasonable in terms of the demographics of North Texas.

However, in looking at the gender demographics of the engineering camps over the years, typically female participation was no higher than 30\% with the 2008 camps averaging 24\% female. Obviously this does not match the demographics of the available population. Therefore the College began considering ways to increase the participation of young women in the engineering outreach activities. First, the College investigated what activities were already available locally in order to determine where to target its activities. Second, literature on girls and engineering was reviewed to look for strategies that would be useful in increasing girls' participation. From this work, a plan for Girlgeneering was developed.

Based on the literature and on existing girls' activities, it was determined to offer a girls-only summer engineering camp modeled on the Entry to Engineering day camp for middle school young women. The goals for offering a girls only camp were to increase interest in engineering by combating stereotypes, creating connections, reducing the issue of competition for resources with boys, and demonstrating the real-world social impact of engineering. The Girlgeneering camp was designed to introduce a variety of engineering fields to young women by showing how these areas of engineering connect to personal issues, social concerns, and community interests. The girls-only nature of the camp was planned to reduce the distraction of competition with boys and to allow the young women to collaborate with one another. Likewise the girls-only structure was anticipated to reduce the effects of any unintentional negative gender bias in presentations and activities. Also after attending the camp, the girls should also be able to counter engineering stereotypes among their peers and should be more able to recognize the impact of engineering on a personal, social, and community level. Increasing the girl's' positive engineering interest through the Girlgeneering camp should result in increased recruitment to engineering, science, technology, and math classes and careers.

The unique components of the Girlgeneering camp are described later in this paper and include a tailored individual hands-on engineering project for the girls, a high percentage of female faculty presenters interacting with the campers, and social and community foci in the presentation and project topics.

\section{Camp Structure}

The structure of the Entry to Engineering camp and the Girlgeneering camp are similar since Girlgeneering was designed based on the successful model of the Engineering and Computer Science Summer Camps. At both of these summer camps students spend their days participating in engineering presentations with professors and graduate students, visiting the engineering labs, talking with engineering professors and students, working on hands-on engineering team 
projects, taking field trips to see engineering applications at work, and learning exactly what engineers do. The students get to experience college life during their week on the UTA campus visiting the engineering buildings and the university center cafeteria. A team of engineering professors, graduate and undergraduate students from all of the UTA engineering departments aerospace, biomedical, civil, computer science, electrical, environmental, industrial, materials science, and mechanical - present the summer camp programs. The instructors provide hands-on activities in addition to their lectures to show a sampling of many kinds of things that engineers do. The camps are run by a team of approximately 20 UTA student Camp Facilitators under the direction of Dr. Tiernan and Mr. Broussard. Approximately 50 middle or high school students attend each week of the engineering camps each summer. Each camp also has 3 math, science, and technology teacher participants who attend all the activities as campers and receive a stipend. The teacher participants then take what they learn back to their classrooms to encourage even more students than those that can directly attend the camps.

The camp structure for the 2008 Entry to Engineering camp and the other two Engineering and Computer Science Summer Camps at UT Arlington included a Sunday night orientation with campers and parents. Monday started with a welcome session from the UTA Engineering Dean followed by a safety lecture. After the safety lecture the first engineering presentation was, and has historically been, a talk by our FSAE advisor and ME professor Dr. Bob Woods and then a visit to the FSAE Race Car planning rooms and workshops to see some of the race cars that UTA students have built and competed with. After lunch on Monday, all campers had a presentation from an engineering faculty member. After this the day campers got the team project introduction during which the campers hear about the different types of hands-on team projects they can work on, they learn about the requirements to create and document the engineering project, they choose their first, second and third choices of projects, they separate into project areas and then within each project area the campers are split into project teams of two to four campers. Time permitting, the teams then get a first taste of the details of their project on Monday.

On Tuesdays and Thursdays the campers go on field trips in the morning and then hear presentations and work on team projects in the afternoon. On Wednesday day campers have a mix of presentations and team project work time. On Friday in all camps the students have time in the morning to finish up any team project work then the bulk of the day is spent in team project presentations and demonstrations. When these are done the campers typically visit the planetarium while the awards judging is completed. Then the campers' families join the campers, we serve dinner, and then we hold the camp awards ceremony giving awards for the best team projects, various camp awards, and certificates for the campers. At the conclusion of the awards, everyone is dismissed, and camp is over.

This summer the Engineering and Computer Science Summer Camps offered six different team projects that student could choose from. For electrical engineering, the campers could choose to learn about designing digital circuits for a particular need, such as a digital lock, and then creating that circuit on a breadboard to demonstrate feasibility. For aerospace engineering, the campers used a simulation tool from NASA to design an air launched paper rocket and then built the rocket they designed. For computer science engineering, the campers investigated a simple video game program with sprites and scripts and then added functionality and visual 
modifications to create their own games. For civil engineering, the students designed and constructed a model of a bridge of a certain size to hold static and dynamic loads. For mechanical engineering, the campers used Lego Mindstorm robots and software to build and program a robot to perform a specific mission of recovering stolen weapons in disputed territory in a military simulation. Finally in the Engineering and Computer Science Summer Camps, we offered a new project in the interdisciplinary area of autonomous vehicles in which students calibrated and programmed a robot to carry a platform of sensors to a specified location for use. The team projects required the students to build the engineering project, write a short technical paper about their project, and develop a Powerpoint presentation from the paper to present on Friday of the camp. The total time spent on team projects was about 6.5 hours during the week.

The presentations by faculty during the camp days gave campers a taste of different aspects of our eight engineering disciplines. Most faculty presentations included a short video or Powerpoint presentation, some demos or manipulatives, a hands-on activity, or a lab visit. The presentations were from aerospace, bioengineering, civil, computer science, electrical, industrial, mechanical, and materials science engineering. There were also presentations about chemistry and physics as well. The presentations were from an hour to an hour and a half in length. Most presentations covered a particular professor's interest in their field rather than covering the entire discipline. Therefore the civil engineering presentation focused on air quality assessment when one professor spoke and then on water resources and use when a different professor spoke in another camp week. The electrical engineering presentation introduced concepts of RFID and how that technology affects the students daily. The computer science engineering presentation talked about creating databases of human motion and motion capture and had a live demonstration of recording human movement from a suit with sensors in it. The industrial engineering presentation gave something of an overview of the field of IE and then had student's do a hands-on activity which demonstrated process improvement using Legos. The aerospace presentation took students to the UTA wind tunnel and had them build paper airplanes and test them. Another presentation introduced nanotechnology, yet another looked at drug-eluding heart stents, and a third gave an overview of the field of materials science engineering. Each year the presentations vary as new faculty become involved in the camps.

This year's field trips for Entry to Engineering included a visit to the TCC fire training academy and its automated systems for simulating and measuring fires and fire control, and a behind-thescenes tour of Bass Performance Hall.

The structure of the new Girlgeneering Camp was based on our successful existing co-ed Engineering and Computer Science Summer Camps and included, faculty presentations with activities, engineering field trips, and a team project. The Girlgeneering Camp also included a hands-on engineering individual project that the girls were able to take home with them on the first day of camp. The individual project was an innovation for the girls-only camp. The engineering faculty presentations included hands-on activities, lab tours, and/or live demonstrations and represented each of eight UT Arlington engineering departments. The Girlgeneering field trips took the campers to businesses and organizations with engineering related themes. The field trips for this camp included a behind-the-scenes tour of Bass Performance Hall with the Hall's Director of Operations, a Mechanical Engineering graduate of UT Arlington. For the team project, the girls chose one of six projects in aerospace, biomedical, 
civil, computer science, electrical, or mechanical engineering. Each project required the team of campers to practice engineering design and implementation, documentation and presentation requirements and each project was led by a UT Arlington student engineering mentor. The inclusion of individual projects that the students could make and take with them was a unique feature of the Girlgeneering camp. For the Girlgeneering camp, the girls created secret noisemakers wiring up buzzers to batteries and a switch and storing the whole thing in a small glass purse so that the unwary would pick up the purse and set off the buzzer. They were also able to create an LED night light wiring up three colored LEDs to resisters, a switch and batteries also housed in another glass purse. The projects were created by three of the camp staffers who wrote the instructions and created parts kits for all of the girls to use. The glass purse projects were partially funded through a \$500 grant from the PBS program "Design Squad" sponsored by the ASCE.

Ten faculty members and Ph.D. students from the College of Engineering provided the engineering presentations on topics from Aerospace, Bioengineering, Civil, Computer Science, Electrical, Material Science, Mechanical Engineering, and Nanotechnology. Four faculty and students from the College of Science presented lectures on Physics and Chemistry. In keeping with the goals of the camp, the camp director, Dr. Tiernan, arranged for the majority of the faculty members and Ph.D. students who presented to be female. This is unusual since the percentage of women faculty in the College of Engineering overall is currently at less than $15 \%$ of the total faculty members. Additionally, in order to be more appealing to young women, each presenter was asked to focus their content in such a way as to show how their engineering area had personal, social, or societal impact in order to help capture the girls' interest. For example, the computer science presenter discussed one project in which her lab is building a glassesmounted device to assist the blind by capturing visual data, interpreting it, and audibly feeding this information to the wearer of the device at speeds which will allow the blind person to safely walk or navigate in a changing physical environment by relying on this device. Another presenter, after discussing the causes and prevention of atherosclerosis, then described how a stent, a biomedical device for holding open an artery, can help reduce the problems of clogged arteries in the heart and how her lab is researching better designs and coatings for stents.

Overall the structure and schedule of Girlgeneering was quite similar to Entry to Engineering. However, while modeled on the co-ed Entry camp, the Girlgeneering camp was also designed to promote gender equity and present engineering and computer science in ways that address young women's preferences ${ }^{1}$. To show diversity, the camp included as many of our women faculty as possible as our camp presenters along with faculty of various ethnicities. Drawing on research by Dr. Denise Agosto on girl's preferences for electronic information design and content ${ }^{2}$ the various presentations were designed and given in a way that demonstrated inclusion and gave real-world context to the concepts. The engineering topics built personal identification with the girls and demonstrated how engineering supports social connectivity. These types of presentations showed that engineers are concerned with the big picture and with how computing and engineering can solve problems in the world - which addresses another area of women's concerns with the field of engineering ${ }^{3}$. The team projects for the campers promoted collaboration and, again, were be modified somewhat from the Entry team projects to demonstrate real-world context and social connections for the campers. The goal for these 
approaches was to overcome any stereotypes that the campers may have come in with and to show the challenge, the fun, and the opportunities that are found in engineering

\section{Camp Preparation}

Since the Girlgeneering camp was modeled on the Entry to Engineering camp, much of the preparation for the two camps was similar. Both required logistics planning on the UT Arlington campus, coordinating field trips, hiring of staff, making arrangements with faculty presenters, acquiring material for projects and activities, and advertising the camps to encourage camper participation.

In some of these areas however, there were some notable differences between the two camps. One interesting area of difference was in field trip planning and coordination. Mr. Lynard Broussard, the Entry and Girlgeneering Co-Director, was responsible for field trip arrangements for both camps. To arrange field trips for groups of $50+$ students requires significant communication and negotiation with the companies and organizations that the camp hopes to visit. Since the Girlgeneering camp occurred later in the summer than the Entry camp, Mr. Broussard contacted some companies multiple times about hosting different groups of campers for the field trips. When he was planning and booking fieldtrips for each camp, he noticed that company representatives that he spoke with during the course of booking fieldtrips seemed to be very surprised, but fascinated by the idea of having an all-girls camp and were extremely inquisitive about this program. Once they had heard about the Girlgeneering camp, these company representatives appeared very determined to accommodate the camp, even when things did not pan out. Further, after explaining what we planned to accomplish by hosting such a camp, Mr. Broussard received quite a few queries about available spots for the children of the various company reps. In discussing this phenomenon, we surmised that the technology companies acknowledge the need for more women in engineering fields and many have programs to address this need. Thus the idea of the girls camp supported not only the goals of UT Arlington Engineering but also their own corporate goals as well.

In addition to differences in field trip planning, there were also some differences in arranging for faculty presenters for the Girlgeneering camp. For the Entry to Engineering camp, a number of faculty members were contacted based on previous participation in summer camps or interest they had expressed in helping with outreach. The final roster of presenters was a mix of favorite veterans and new enthusiastic faculty members and Ph.D. students with the primary criteria of making sure all of the engineering departments were represented. The Entry presenters included male and female faculty and graduate students of diverse ethnicities. Out of nine engineering presentations in the Entry camps, two were presented by females. This is a relatively apt representation of the proportion of female to male faculty in the College of Engineering. For Girlgeneering, Dr. Tiernan made a specific appeal to the female faculty to participate in the camp and present. Based on this appeal, out of eight engineering presentations, six were given by female faculty or graduate students. This allowed the campers to see female engineering role models.

The student camp staff also served as role models for the campers of both Entry and Girlgeneering. Over the history of the summer camps, the proportion of female camp staffers is 
generally about $50 \%$ of the camp staff overall which is interesting considering that the female engineering student population from which the staff is drawn in only about $20 \%$ female. This year, since Girlgeneering was a new camp, the decision was made to try to staff Girlgeneering with experienced staffers rather than seeking additional female camp staff. The camp staffers for Girlgeneering had, all but one, also worked in either the Entry camp or a previous summer camp and the ratio of female to male staffers was about 50:50. The camp staff who experienced both the Entry camp and Girlgeneering had some interesting observations which are noted below.

While the camp staff preparation was virtually the same for Entry and Girlgeneering, there was one entirely new feature of Girlgeneering that required a significant amount of preparation. For the Girlgeneering camp it was decided to have the girls create an individual engineering project on the first day of camp that they could take home with them that night. The goal was for them to have fun, create something good-looking and entertaining, and do some hands-on engineering in order to generate enthusiasm for the rest of the camp week. The rationale was that this would encourage any campers who might have been hesitant about whether an engineering camp would be "girly" or fun. The actual form of the project was suggested by a small (approx. 4" x 4" x 2") glass purse that the Camp Director spied in large quantities in a local store. Since glass is very durable and is an insulator, Dr. Tiernan decided that the glass purses could be the housing for some type of small electrical project. Eventually, student camp staffers developed three small electrical projects that could each be housed in a glass purse: an LED nightlight, a surprise buzzer, and an electromagnet. Each was powered by a 9-volt battery. In order to make these project successful for the girls, all the needed instructions and materials were pre-packaged together prior to the camp. A group of student camp staffers built demos following the directions to test them and assembled baggies of insulated wires with stripped ends, battery holders, and various components such as the LEDS or the buzzer for each girl for each project. The development of the project instructions, the testing, and the kit making took about three weeks of preparation time.

A final difference in camp planning occurred in how the two camps were advertised. The Entry to Engineering camp is part of our long-running camp program so there are teachers and parents who look for that activity each year. There is a camp website which contains a camp description, pictures of previous camps, and the application materials for the camp. Teachers are also notified about the camps through e-mail and with flyers so that they can recommend it to their students. The camps are also listed in various summer activity guides produced locally as well as online. With the addition of Girlgeneering it was decided to try to reach additional populations as well. This included advertising the Girlgeneering camp through the local Girl Scouts affiliate and through a network called the Texas Girls Collaborative Project. Flyers were also made available at local girl-focused events, such as Girl University.

\section{Camp Realization}

The planning and preparation for Girlgeneering was, as has been described, somewhat more than that required for the Entry to Engineering camp, but much of that was the result of the camp's newness. The actual implementation of the camp brought with it a number of differences the Entry camp and Girlgeneering. 
On the first day of camp, Monday, the individual engineering project was a wild success! The girls worked at tables in groups with the camp staff floating between to assist. Girls helped each other as needed. The activity was challenging but every camper completed at least one of the two available projects and most campers completed two unique projects to take home. At pickup time that day nearly every camper's first words were “Look what I did!” The girls clearly felt that they had successfully completed an engineering activity. The positive reaction to the project was so strong that next year, all of the Engineering and Computer Science summer camps will incorporate a take home individual project.

While not as dramatic, there were other differences noted between the Entry camp and the Girlgeneering camp. As one camp staff said at the end of the second day, "The girls are so EASY!” meaning that managing the group of female campers was much simpler for the camp staff than the management of the co-ed group. In general the camp staffers reported that although the girls were often chatty, they nonetheless listened to direction and paid attention substantially better than did the boys in the co-ed camps. In Girlgeneering, interestingly, the camp staff felt that fewer subgroups or cliques were formed during the camp than during the Entry camp. Mr. Broussard, the Co-Director noticed that the young ladies that attended the Girlgeneering camp felt more comfortable asking and answering questions and that they seemed much more relaxed than their female counterparts in the Entry to Engineering camp. He felt that the young ladies appeared to thrive in an environment where they did not have to compete with boisterous young men and that during the team projects each group did an excellent job creating a sense of camaraderie and support amongst one another. He contrasts this with the Entry and other co-ed camps where girls and boys constructively challenge each other during projects and hands-on activities but notes that, from his experience, boys tend to dominate discussions and the girls are relegated to the background.

Since this was the inaugural year of the Girlgeneering camp, those campers were asked to fill out daily surveys about each aspect of the camp. For each activity, the girls were asked if the topic was interesting, if the presentation or activity was enjoyable, and if they learned something new. The survey scale was 1 to 10 with 10 being the highest rating.

Overall, the Engineering and Science presentations had an average rating of 7.8 for how much the students enjoyed the presentations, an 8.0 rating for whether the topic was interesting to the students, and an 8.4 rating indicating that the campers learned something new from the presentations. As might be expected, the field trips earned high marks average a 9.0 rating across the board. For the individual projects, there weren't any presentations - just instructions and hands-on assistance but even so this got an 8.7 rating for the presentation. The interest rating was 9.0 and the learning rating was 8.8 for the individual projects. The team projects got 8.7 for presentations - these varied significantly from project to project due to the nature of each project. The team project interest rating was 8.8 and the learning rating was 8.7. Additional survey data from parents and campers following the camp is still being collated. Overall it was felt that the activities of the Girlgeneering camp were all positively received by the campers. 


\section{Benefits}

For many years, the UT Arlington College of Engineering has offered its summer camp program to pre-college students. For UT Arlington the benefits include the students' increased interest in engineering and computer science for their future careers, the opportunity to promote UT Arlington's broad and diverse engineering programs to their parents and the community, and the chance to bring students to UT Arlington to excite them about the campus and the school for their future college choices. Both Entry to Engineering and Girlgeneering provide these benefits.

In addition, the Girlgeneering camp can offer young women a chance to learn about engineering in way that attracts them to the field and increases their future opportunities. The Girlgeneering camp can help break stereotypes about engineering while showing how meaningful, exciting, and fun the fields of engineering are. Getting young women interested in engineering is crucial to the goal of creating male to female parity in the engineering field.

\section{Plans}

Based on the positive results from the Girlgeneering camp, this program will become a permanent part of the UT Arlington Engineering Summer Programs. Girls will still have the option to attend any of the co-ed camps as well as the choice of the girls-only camp.

The Girlgeneering experience will also inform the planning for the Engineering and Computer Science co-ed camps. Future co-ed camps will have an individual engineering project for campers to complete and take home. The faculty presenters in future co-ed camps will also be asked to show in their presentations how their topic has personal, social, and/or societal impact as well as talking about the cool, "techie" aspects. Both the individual project and the personal and social focus will appeal to the girls in the co-ed camps while still capturing the boys' attention.

Having seen such positive feedback from the first Girlgeneering camp, the UT Arlington College of Engineering is excited about the outreach possibilities offered by continuing the girls-only camp in conjunction with its successful existing co-ed camps. The College of Engineering looks forward to contributing to an increase of girls choosing to pursue engineering in their future for their benefit and that of society.

\section{References}

1. Sanders, Jo, 1994, Lifting the Barrier, Center for Gender Equity, Washington Research Institute, Seattle, Jo Sanders Publications, http://www.josanders.com/educators.html\#pdf.

2. Agosto, Denise, 2000, “A Study of Girls’ and Young Women’s Electronic Information Design and Content Preferences”, Girls Tech, Douglass College. 30 Nov. 2007 http://girlstech.douglass.rutgers.edu/gt summary.html .

3. Margolis, Jane, Allan Fisher, and Faye Miller, 1999, "Caring about Connections: Gender and Computing”, IEEE Technology and Society, Vol. 18, Issue 4, Winter 1999-2000, pgs. 13 -20, http://ieeexplore.ieee.org/stamp/stamp.jsp?arnumber=808844\&isnumber=17517.

4. Sanders, Jo, 2005, “Gender and Technology in Education: A Research Review”. June, 2005, http://www.josanders.com/educators.html\#pdf. 


\section{LYNN PETERSON}

Dr. Lynn Peterson is Senior Associate Dean in the College of Engineering at the University of Texas at Arlington. She was the 1992 recipient of the Robert Q. Lee Award for Excellence in Engineering Education, and in 1997 was inducted into the UT Arlington Academy of Distinguished Teachers. Dr. Peterson's research focuses on artificial intelligence applications to medicine, specifically on knowledge discovery in medical databases.

\section{CARTER TIERNAN}

Dr. J. Carter M. Tiernan is the Assistant Dean for Student Affairs in the College of Engineering and a Senior Lecturer in Computer Science and Engineering at the University of Texas at Arlington. As Assistant Dean, Dr. Tiernan has responsibility for recruiting and K-12 outreach, and coordination of engineering student activities. In the CSE department Dr. Tiernan has responsibility for undergraduate teaching and high school outreach and served for many years as an undergraduate advisor. Dr. Tiernan is currently interested in the research areas of artificial intelligence, engineering education, computer curriculum at the elementary level and women in engineering issues.

\section{LYNARD BROUSSARD}

Mr. Lynard Broussard is the Undergraduate Recruiter for the College of Engineering. He has responsibility for visiting high schools and college fairs, communicating with prospective students, and managing the Engineering Student Ambassadors - a group of peer recruiters who accompany him. 